\title{
PENGEMBANGAN SOCIAL ENGAGEMENT MELALUI MEDIA SITUS JEJARING UNTUK OUR DREAM INDONESIA
}

\author{
Aditia Sovia Pramudita ${ }^{1}$, Tamadara Hilman ${ }^{2}$, Asaretkha Adjane Annisawati ${ }^{3}$ \\ D4 Logistik Bisnis, Politeknik Pos Indonesia ${ }^{1}$ \\ aditiasovia@poltekpos.ac.id \\ D4 Logistik Bisnis, Politeknik Pos Indonesia² \\ tamadarahilman@poltekpos.ac.id \\ D4 Manajemen Bisnis, Politeknik Pos Indonesia ${ }^{3}$ \\ asaretkha@poltekpos.ac.id
}

\begin{abstract}
Abstrak
Anak berkebutuhan khusus (ABK) tunarunggu merupakan individu-individu yang mempunyai karakteristik yang berbeda dari individu lainnya yang dipandang normal oleh masyarakat pada umumnya. Secara lebih khusus, ABK tunarunggu menunjukkan ketidakberfungsinya indera pendengaran dan menjadikan bebrapa anak menjadi tunawicara pula. Oleh karena itu, dibutuhkan penangan yang khusus bagi ABK sehingga kelak di masa yang akan datang ABK bisa diperlakukan sama pentingnya dengan anak normal lainnya. Our Dream Indonesia sebagai salah satu pusat terapi kembang anak dan remaja berkebutuhan khusus. Berbagai macam pelatihan dilakukan Our Dream Indonesia untuk mendidik ABK agar ABK dapat mengembangkan kemampuan yang mereka miliki sehingga kelak kemampuan tersebut dapat menjadi manfaat bagi lingkungan sekitar. Pelatihan yang diberikan pada PKM ini ada bertujuan membantu Our Dream Indonesia dalam mengembangkan social engagement untuk meningkatkan awareness masyarakat, terutama dalam hal pentingnya mendukung pelatihan yang dibutuhkan oleh ABK. Social engagement merupakan pengembangan hubungan dengan masyarakat untuk membantu memberdayakan aktivitas yang ditawarkan oleh Our Dream Indonesia melalui pelayanannya dan komunikasi kepada komunitas. Salah satu media yang diharapkan dapat membantu pengembangan social engagement tersebut melalui situs jejaring (website) untuk Our Dream Indonesia.
\end{abstract}

Kata Kunci: ABK, social engagement, website

\begin{abstract}
Children with special needs are individuals who have different characteristics from other individuals who are considered normal by society in general. More specifically, Children with special needs show the malfunctioning of the sense of hearing and makes some children become speechless as well. Therefore, special handling for children with special needs are needed so that in the future they can be treated as important as other normal children. Our Dream Indonesia as one of the development centers for children and adolescent with special needs. Various types of training are conducted by Our Dream Indonesia to educate $A B K$ so that ABK can develop their abilities so that later these abilities can benefit the surrounding environment. The training is aimed at helping Our Dream Indonesia to develop social engagement in order to increase public awareness, especially in the importance of supporting special needs children. Social engagement is the development of relationships with the community to help empower activities offered by Our Dream Indonesia through its services and communication to the community. One of the media that is expected to help the development of social engagement is through a website for Our Dream Indonesia.
\end{abstract}

Keywords: special needs children, social engagement, website 


\section{PENDAHULUAN}

Undang-Undang No.20 Tahun 2003 tentang Sistem Pendidikan Nasional Pasal 32 disebutkan bahwa: "Pendidikan khusus (pendidikan luar biasa) merupakan pendidikan bagi peserta didik yang memiliki tingkat kesulitan dalam mengikuti proses pembelajaran karena kelainan fisik, emosional, mental, sosial”. Ketetapan dalam Undang-Undang No. 20 Tahun 2003 tersebut sangat berarti bagi ABK (Anak Berkebutuhan Khusus), karena memberi landasan yang kuat bahwa ABK mempunyai hak yang sama dalam mendapatkan pendidikan dan pengajaran. Tanggapan masyarakat kepada ABK sendiri saat ini memang tidak selalu negatif. Terdapat juga pandangan masyarakat tentang ABK atau anak cacat dipandang sebagai anak yang harus dikasihani atau disantuni. Sehingga tak jarang ditemukan di dalam masyarakat, kelompok-kelompok penyantun orang cacat dan merawatnya dengan memberikan keterampilan atau pelatihan tertentu kepada penyandang cacat tersebut. Lebih jauh lagi, banyak juga komunitas dari para remaja dan para orangtua untuk memahami pemahaman tentang ABK yang tidak selalu tentang kecacatannya tetapi juga mereka memiliki bakat yang harus diolah dengan dukungan atau motivasi dari sekeliling anak berkebutuhan khusus tersebut. Pandangan positif tersebutlah yang diharapkan muncul dari masyarakat terkait dengan keberadaan ABK ini.

Melihat pada kondisi tersebut, paradigm di masyarakat terkait dengan ABK harus diubah sedikit demi sedikit sehingga ABK tidak lagi dianggap sebagai manusia yang mengganggu.Saat ini salah satu cara untuk dapat mengubah paradigm masyarakat adalah dengan memberikan pengetahuan kepada masyarakat bahwa $\mathrm{ABK}$ merupakan manusia yang dapat memiliki bakat dan dapat menghasilkan karya yang luar biasa. Hal tersebutlah yang perlu dikomunikasikan kepada masyarakat sehinggamasyarakat dapat mengerti bagaimana ABK itu dan besar harapan mereka dapat berperan serta untuk mengembangkan bakat yang dimiliki oleh ABK setelah mereka paham dan sadar mengenai bakat yang dimiliki oleh ABK (social engagement). Social engagement adalah suatu peran yang diambil oleh individu terhadap masyarakat secara umum. Hal tersebutlah yang coba untuk dibangun dengan tujuan agar ABK memiliki hak yang sama dengan anak yang tidak memiliki keterbatasan fisik ataupun mental.

Social engagement dapat dibangun melalui banyak cara. Pada program PKM ini, situs jejaring dipilih sebagai media untuk social engagement dikarenakan situs jejaring mampu menggapai berbagai lapisan masyarakat khususnya generasi muda (Pramudita, Yanuar, \& Hilman, 2019). Selain itu, penggunaan situs jejaring sendiri merupakan cara untuk dapat menggapai generasi muda dimana generasi tersebutlah yang memiliki potensi dan kapabilitas untuk dapat berperan mengembangkan ABK ini.

\section{PERMASALAHAN MITRA}

Our Dream Indonesia merupakan lembaga sosial kemanusiaan yang menangani anak-anak berkebutuhan khusus penyandang kelainan syaraf. Autisme, PDD-Nos, Down Syndrome, Cerebral Palsy, Epilepsi, Rett's Syndrome, Conduct Disorder, Mental Retardasi, Gangguan Kepribadian termasuk juga anak-anak berbakat. Our Dream Indonesia sendiri berlokasi di Jalan Sinom no. 5, Turangga, Lengkong, Kota Bandung, Jawa Barat. Dalam rangka pemberdayaan anak-anak berkebutuhan khusus, Our Dream Indonesia memiliki program yang bertujuan untuk melatih motorik anak-anak agar kelak ABK dapat berperan di dalam masyarakat. Berdasarkan kurikulum tersebut Our Dream Indonesia selalu berusaha agar karya mereka dapat dilihat oleh masyarakat luas sehingga hal tersebut juga dapat menjadi sebuah edukasi bagi masyarakat bahwa anak berkebutuhan khusus itu tidak berbeda.Dalam meningkatkan awareness atas kegiatan yang sudah dilaksanakan oleh Our Dream Indonesia, dibutuhkan suatu sarana atau media yang dapat menyebarluaskan informasi mengenai yayasan ini. Hal ini perlu dilaksanakan dengan tujuan untuk mencapai social engagement untuk masyarakat dalam membantu memberdayakan aktivitas yang ditawarkan oleh Our Dream Indonesia. Salah satu media yang dapat digunakan adalah situs jejaring (website) dengan memberikan konten informatif.

Situs jejarang dipilih dikarenakan media tersebut cenderung memiliki biaya yang lebih murah dibandingkan dengan media informasi lainnya dan dapat dilihat oleh banyak orang sehingga impactnya diharapkan dapat lebih besar bila dibandingkan dengan media informasi lainnya. 
Our Dream sendiri saat ini belum memiliki situs jejaring. Hal tersebut membuat Our Dream kesulitan dalam menginformasikan hasil karya ABK kepada masyarakat. Saat ini Our Dream sendiri merasa membutuhkan situs jejaring sebagai media informasi kepada masyarakat luas.

\section{METODE PELAKSANAAN PROGRAM}

Aktivitas yang ditawarkan dalam PKM untuk Our Dream Indonesia adalah dengan rincian sebagai berikut:

1. Pembuatan Situs Jejaring Our Dream Indonesia dengan konten awal yang diperoleh dari pihak Our Dream.

Pembuatan situs jejaring Our Dream Indonesia ini dilakukan dengan tenaga bantuan external yang ahli di bidangnya. Tahapannya dilakukan tetap dengan supervisi dari tim PKM agar tidak terjadi miss concept. Tahapan awal adalah melakukan pembangunan situs jejaring dengan bantuan wordpress sebagai platform awal yang digunakan. Kemudian, tim PKM berkonsultasi dengan pihak Our Dream terkait dengan konten yang perlu dimasukan di awal pembuatan situs jejaring. Berdasarkan hasil diskusi diperoleh konten utama yang akan dimasukan adalah:

- Activity

- Akademik

- Autisme

- Kerajinan

- Outing

- Parenting

- Program Terapi

- Renang

- Senam

2. Pelatihan pengoprasian situs jejaring dalam melakukan maintenance sederhana dan menambahkan konten yang diinginkan di Our Dream.

Pelatihan dilakukan dengan tatap muka langsung kapada penanggung jawab IT di Our Dream Indonesia Bapak Ujang dan Ibu Rahma sebagai penanggung jawab konten. Pelatihan dilakukan langsung di Our Dream Indonesia dikarenakan kesibukan pihak Our Dream Indonesia sehingga pelatihan tidak dapat dilakukan di luar institusi.

Pelatihan dilakukan dengan pembahasan platform. Tim PKM telah membeli template website sehingga dapat digunakan oleh pihak Our Dream Indonesia dengan bebas tanpa berbayar. Template ini memudahkan pihak Our Dream Indonesia untuk dapat menjalankan proses operasional website dengan lebih mudah bahkan untuk orang yang masih awam.

Terkait dengan konten yang harus diangkat sudah diluar kapabilitas tim PKM karena membutuhkan approval dari pihak Our Dream Indonesia sebagai pemilik konten. Hal tersebut telah dikomunikasikan dan pihak Our Dream pun telah menyetujui hal tersebut. PKM ini tidak berhenti hanya sampai pelatihan. Tim PKM memiliki janji apabila terjadi kendala selama satu tahun ke depan tim PKM akan mengatasi masalah tersebut terkait dengan website yang telah dibuat.

\section{KELAYAKAN PERGURUAN TINGGI}

Lembaga Penelitian dan Pengabdian Masyarakat (LPPM) Politeknik Pos Indonesia rutin mengadakan kegiatan pengabdian masyarakat baik dengan pendanaan sendiri ataupun dengan dana yang diperoleh dari Dirjen DIKTI. Kegiatan pengabdian masyarakat ini biasanya dilakukan di wilayah Bandung Raya.

Tim pelaksana kegiatan PKM "Pengembangan Social Engagement melalui media situs jearing untuk our dream indonesia" ini terdiri dari dosen-dosen yang memiliki keahlian yang memadai dan telah berpengalaman dalam bidang ilmu terapan yang sesuai dengan kegiatan ini, yaitu: 
1. Ketua tim merupakan dosen di Prodi D4 Logistik Bisnis Politeknik Pos Indonesia yang mempunyai pengalaman di bidang pemasaran dan kewirausahaan.

2. Anggota tim 1 merupakan dosen di Prodi D4 Manajemen Bisnis Politeknik Pos Indonesia yang mempunyai pengalaman di bidang pemasaran, kewirausahaan, dan penelitian terapan.

3. Anggota tim 2 merupakan dosen di Prodi D4 Logistik Bisnis Politeknik Pos Indonesia yang mempunyai pengalaman di bidang pemasaran dan penelitian terapan.

\section{HASIL YANG DICAPAI}

Program Pengabdian Kepada Masyarakat berupa "Pengembangan Social Engagement melalui media situs jearing untuk our dream indonesiia" oleh tim Politeknik Pos Indonesia dilaksanakan pada tanggal 19 September 2018. Hasil yang dicapai pada program pengabdian pada masyarakat ini merupakan produk berupa website yaitu www.ourdreamindonesia.com. Tujuan dari pembuatan dan pelatihan website ini adalah untuk meningkatkan social engagement masyarakat terhadap Anak Berkebutuhan Khusus (ABK). Situs jejaring ini hingga awal tahun 2019 memiliki rata-rata kunjungan per-bulannya sebanyak 1028 pengunjung. Situs jejaring tersebut dianggap telah memiliki performa yang cukup baik mengingat waktu launching situs jejaring tersebut pun belum genap satu tahun. Diharapkan situs jejaring tersebut dapat terus berkembang sehingga mampu mendatangkan trafik yang lebih tinggi lagi sehingga tujuan pembuatan situs jejaring ini sebagai social engagement dalam pembentukan paradigma masyarakat terkait $\mathrm{ABK}$ pun dapat terpenuhi.

\section{REFERENSI}

Hallahan, D.P. dan Kauffman, J.M. 2006. Exceptional children: An Introduction to Special Education (10 ${ }^{\text {th }}$ edition). Boston: Pearson.

Peraturan Pemerintah Republik Indonesia Nomor 72 tahun 2005

Pramudita, A. S., Yanuar, A., \& Hilman, T. (2019). Business Model Formulation For E-Newspaper In Indonesia ( Case Study: Pikiran Rakyat ) Formulasi Model Bisnis Surat Kabar Elektronik Di Indonesia ( Studi Kasus : Pikiran Rakyat ), 20(1), 15-31.

Purwanti. 2011. Manajemen Pembelajaran PAI bagi Anak Berkebutuhan Khusus: Studi di SDLB Negeri Salatiga. Semarang: Fakultas Tarbiyah IAIN Walisongo Semarang.

Syaiful Bahri dan Zain, Aswan. 2010. Strategi Belajar Mengajar. Jakarta: PT. Asdi Mahasatya. Undang-Undang No. 20 Tahun 2003 tentang Sistem Pendidikan Nasional

https://www.kompasiana.com/usfitriyah/5a180a70fcf68110344696a2/pandangan-tentang-anakberkebutuhan-khusus 